\title{
Covid 19 infection in pregnancy - vertical transmission and lactoferrin
}

\author{
Prof (Dr) Hem Kanta Sarma
}

\author{
Correspondence: Prof (Dr) Hem Kanta Sarma, Professor \& HOD, Department of Obstetrics \\ \& Gynaecology, Jorhat Medical College, Jorhat, Assam, India; \\ Email - sarmahemkanta@gmail.com
}

Distributed under Attribution-Non Commercial-Share Alike 4.0 International (CC BY-NC-SA 4.0)

Emergence of COVID 19 infection since December, 2019 and subsequently leading to COVID 19 pandemic also lead to significant involvement of mother and neonates with its inherent complications. Good number of studies are going on all over the world regarding vertical transmission of COVID 19, most of these are inadequate. Initially most of the studies showed no evidence of vertical transmission ${ }^{1,2}$. Of late some studies are coming up with evidence of presence of COVID 19 viral genome in placental tissue, amniotic fluid, umbilical cord and vaginal tissue - proving some links with vertical transmission ${ }^{3,4}$.

Out of many factors affecting the vertical transmission of COVID 19 infection, lactoferrin may have an important role to play in minimizing the incidence. Large numbers of studies are going on to elucidate the mechanism and impact of lactoferrin in this regard ${ }^{5}$.

\section{Vertical transmission of COVID 19}

This has been an important issue for our speciality from the beginning of the pandemic. It has also been observed that unlike HIV infection vertical transmission of COVID 19 is much less in incidence. Of course many studies have demonstrated presence of IgM antibody of COVID 19 in umbilical cord blood samples of affected individual. Though it is known that IgM molecule cannot cross the placental tissue due to its high molecular weight.

Akhtar H, Patel C, Abuelgasim et $\mathrm{al}^{1}$ from St.George university, London found no evidence to support vertical transmission of SARS-COV-2 infection to the unborn child. Lopes de sousa A, Carvalho H, Oliveiva L, et al also confirmed the same statement showing no evidence of mother to child transmission ${ }^{2}$.
On the other hand recent studies are revealing evidences supporting vertical transmission of SARS-COV-2 infection in varying proportion. Alexander M, Kotlyar, MD Olga, Gechuxhina, et al have found in their systematic review and metaanalysis, an incidence of $3.2 \%$ for vertical transmission ${ }^{6}$. In another study Faluico Forman found 7.1\% incidence for infection of neonates by this route ${ }^{7}$.

\section{Role of lactoferrin}

Lactoferrin is a potent antiviral iron binding protein present in the maternal-fetal interface. In concert with the immune cofactor, maternal lactoferrin modulates chemokine release and lymphocyte migration, thus amplify host defence during pregnancy. It also limits the membrane receptor access to SARS-COV-2 for cellular entry. Lactoferrin reduces viral docking and entry into host cells. Syncytiotrophoblast of placenta stimulates release of lactoferrin which act as a good foetomaternal barrier by effectively modulating the immune response and regulating redox homeostasis in the body. Colostrum and milk contains lactoferrin and provides passive immune response.

SARS-COV 2 genome was detected in umbilical cord plasma. It was also detected in vaginal mucosa of pregnant women and at term placenta, specific IgM and IgG antibody was detected in umbilical cord blood sample and in milk specimen $^{3}$.

Placental positivity of SARS COV 2 has been reported in selected cases but infection or viral disease in newborn is very uncommon ${ }^{9}$. This may be due to -

1. Host genetic factor

2. Unique SARS COV 2 genetic variant

3. Production of high load of maternal antibody virus immune complex. 
Lactoferrin has extensive broad spectrum antiviral property ${ }^{5}$. Enzymatic digestion of lactoferrin results in generation of antimicrobial peptides which display antimicrobial property with greater potency ${ }^{8}$.

\section{Conclusion}

Vertical transmission of SARS COV 2 has been proved. Of course incidence is relatively low. Further studies prospective and large series are required. Studies on lactoferrin and on its role in prevention and treatment of COVID 19 infection have given some positive results which may vary in due course of time be of paramount importance to give some relief from this pandemic.

\section{Conflict of interest: None. Disclaimer: Nil.}

\section{References}

1. Akhtar H, Patel C, Abuelgasim E, Harky A. COVID 19 (SARS-COV-2 ) Infection in pregnancy : A systematic review. Gynecol Obstet Invest. 2020; 85; 295-306.

2. Lopes de Sousa A, Carvalho H, Oliverira L, Schneider G, Lucas Silva Camargo C, Watanabe E, et al. Effects of COVID 19 Infection during pregnancy and Neonatal prognosis: what is the Evidence? InT. J. Environ. Res. Public Health. 2020. 17(11): 10.3390/ijerph17114176

3. Fenizia C, Biasin M, Cetin J, et al. Analysis of SARS COV 2 vertical transmission during pregnancy. Nat Commun 11, 5128 (2020). https: //doi. org /10.1038/s41467-020-18933-4.

4. Vivanti AJ, Vauloup-Fellous C, Prevot S, Zupan V, Suffee C, Do Cao J, et al. Transplacental transmission of SARS COV 2 infection. Nat Commun. 2020 Jul 14; 11(1): 3572.

5. Wang Y, Wang P, Wang H, Luo Y, Wan L, Jiang $\mathrm{M}$, et al. Lactoferrin for the treatment of COVID 19 (Review). Exp Ther Med. 2020 Dec; 20(6): 272.

6. Kotlyar AM, Grechukhina O, Chen A, Popkhadze $\mathrm{S}$, Grimshaw A, Tal O, et al. Vertical transmission of corona virus disease 2019: a systematic review and meta-analysis. Am J Obstet Gynecol. 2021 Jan; 224(1): 35-53.e3.

7. Fornari F. Vertical transmission of COVID 19 - a systematic review. J Pediatr Perinatol Child Health. 2020; 4 (2): 7-13

8. Sinha M, Kaushik S, Kaur P, Sharma S, Singh TP. Antimicrobial Lactoferrin peptides: The hidden players in the protective function of a multifactorial protein. International Journal of Peptides. 2020; 2013: Article ID 390230.

9. Fachetti F, Bugatti M, Cancila V, et al. SARSCoV2 vertical transmission with adverse effects on the newborn revealed through integrated immunehistochemical, electron microscopy and molecular analyses of Placenta. Lancet. 2020; 59: 102951. 